\title{
EARTHQUAKE SHAKE: A REGULATORY RECIPE FOR QUAKE STRICKEN KAIKOURA, NEW ZEALAND
}

\author{
KATE MADSEN \\ Director, Paua Planning Ltd, Auckland.
}

\begin{abstract}
Earthquakes and their aftermath have played a big part in the lives of many New Zealander's over the past five years - and while Kiwis are resilient, the tourism sector (as our largest single export industry in terms of foreign exchange earnings) has suffered, particularly in the quake-hit areas of Christchurch and Kaikoura. An integrated approach between local and central government, tourism bodies, communities and civil defence is required in forming both pre-emptive and recovery methodologies.

Through the lens of the New Zealand regulatory planning framework, we will discuss the current situation (three months post-earthquake) in Kaikoura. In addition, we will be exploring strategies and tools to assist rather than constrain tourism operators and operations during, and subsequent to, any future natural disasters. Although seismic activity seems to have increased over the past ten years, it could be assumed that little has been done to refine or instigate regulatory measures to respond to the specific issue of maintaining and/or improving sustainable tourism in NZ.

A series of photographs by a top NZ social media photographer and environmental advocate are included to illustrate the scope and impact of the recent 7.8 magnitude Kaikoura earthquake (14 November 2016). We will outline problems encountered by tourism operators, the existing regulatory local and central government measures in place to avoid/remedy/mitigate effects of natural disasters on the tourism industry, and respond with potential long term strategic options to overcome these identified obstacles.

Keywords: civil defence, local government, natural hazard, regulatory planning, resilience, sustainability, tourism.
\end{abstract}

\section{INTRODUCTION}

Kaikoura is one of New Zealand's tourist meccas, famous for whale watching, seal swimming and other marine related activities, all experienced through a lens of breath-taking scenery. It is also the first community in New Zealand and second in the world to embrace the 'EarthCheck' program, which is a global tourism certification standard birthed from the principles of Agenda 21 (the United Nations action for climate change). This has included initiatives relating to zero waste, energy efficiency, tree planting by tourists, water quality projects, marine protection and biodiversity.

Continuing to set the scene for discussion, it is noted that visitor arrivals to New Zealand set a new record to 3.5 million in the December 2016 year, a 12\% increase from 2015, and

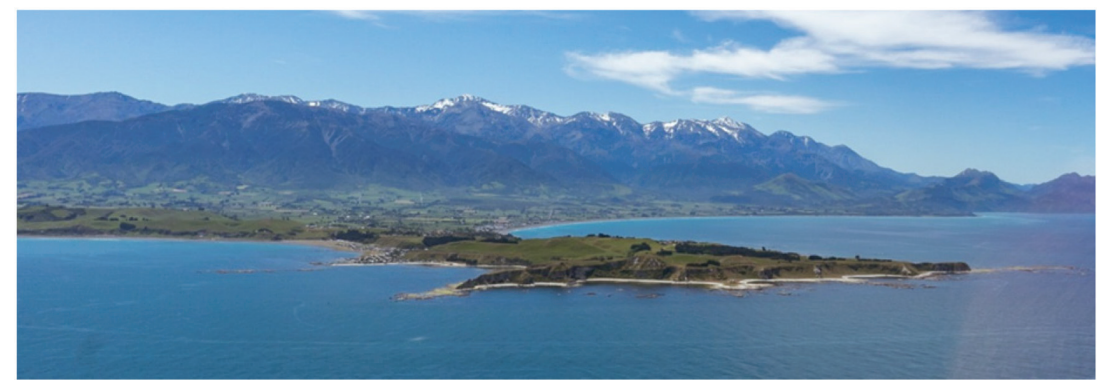

Figure 1: Kaikoura, New Zealand. (Source: Wings over Whales flight, 11 Feb 2017). 
this is forecast to expand to 4.5 million by 2022 [1]. At present, according to David Simmons (Professor of Tourism, Lincoln University), this equates to a city of tourists the size of Dunedin (120,000 or 2.8\% of New Zealand's population) [2] moving across the landscape daily. The impacts of this cannot be under-estimated.

Tourism directly contributes $\$ 12.9$ billion (5.6\%) to New Zealand total GDP, with a further $\$ 9.8$ billion (4.3\%) indirectly contributed. This is a significant industry for New Zealand, and for Kaikoura, where \$109 million tourist dollars are estimated to have been spent in 2016 [3].

Unfortunately, New Zealand also sits precariously astride an active boundary between two large tectonic plates of the Earth's crust. Regional geological mapping has previously identified 14 areas of known or suspected active faults and/or folds within the Kaikoura District [4]. As a natural consequence of this, the tourism sector is vulnerable to the impacts of large disasters, and '...may be subjected to prolonged reduction in visitation, damage to critical infrastructure and negative media attention.' [5]. Even before the 7.8 magnitude earthquake on 14 November 2016, experts at the Institute of Geological and Nuclear Sciences Ltd (GNS Science) were recommending that specific vulnerabilities within the Kaikoura District be identified (such as berthing facilities at the marina, the major coastal highway/railway routes and low intensity residential development areas) and that contingency plans for first response emergency management and disaster recover in the event of an earthquake be prioritised by regional and territorial local authorities.

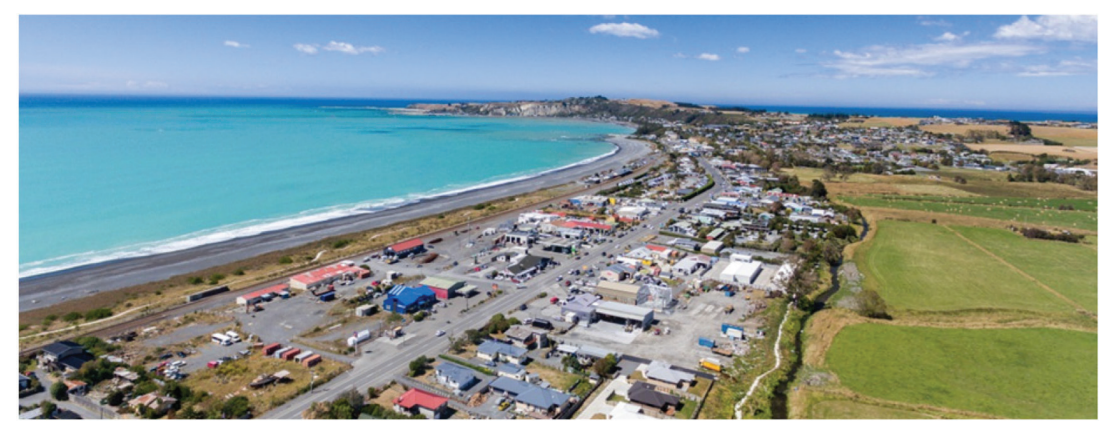

Figure 2: Kaikoura Township. (Source: Wings over Whales flight, 11 Feb 2017).

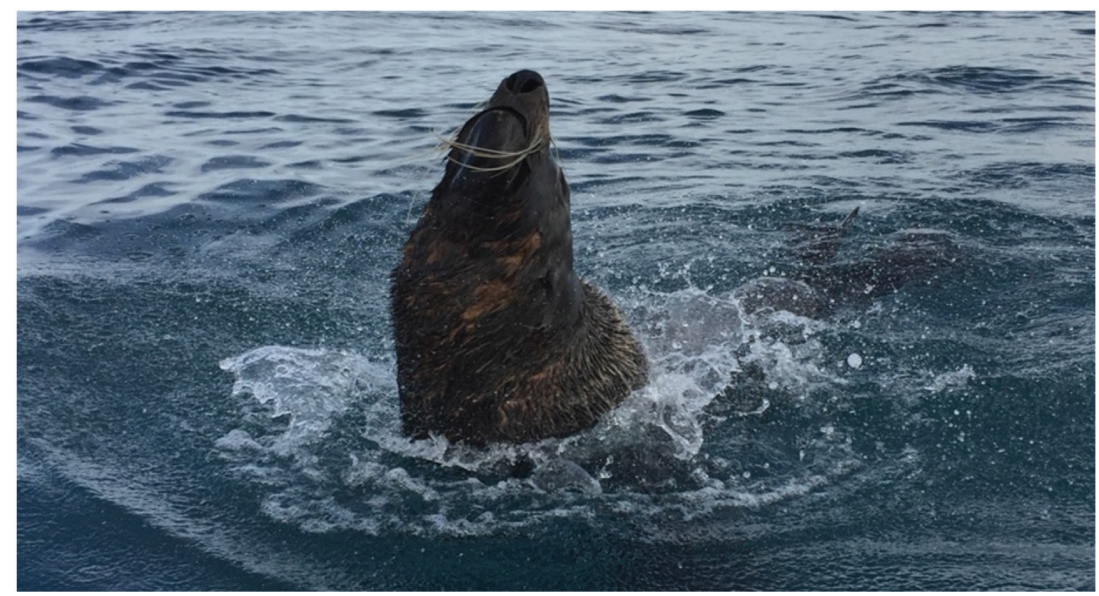

Figure 3: Fur seal up close. (Source: Excursion with 'Kaikoura Kayaks', 12 Feb 2017). 


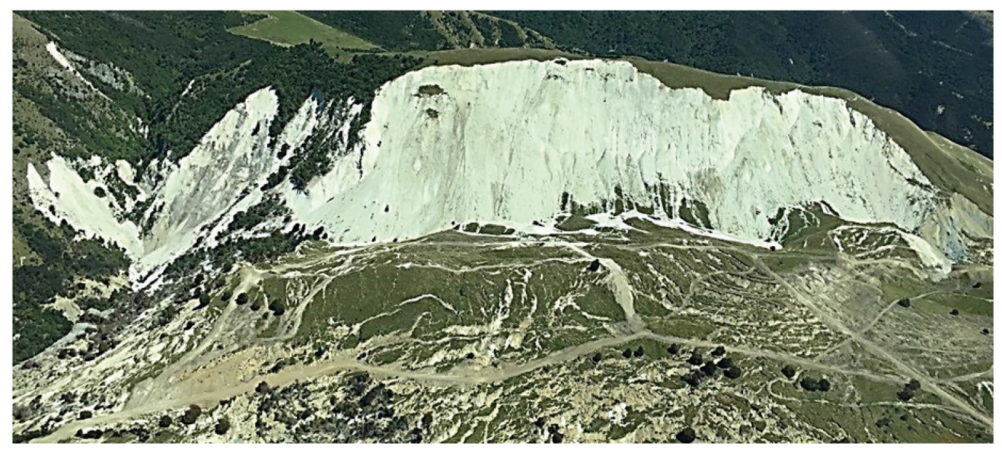

Figure 4: Ruptured Local Landscape - Entire hillside collapse. (Source: Wings over Whales flight, 11 Feb 2017).

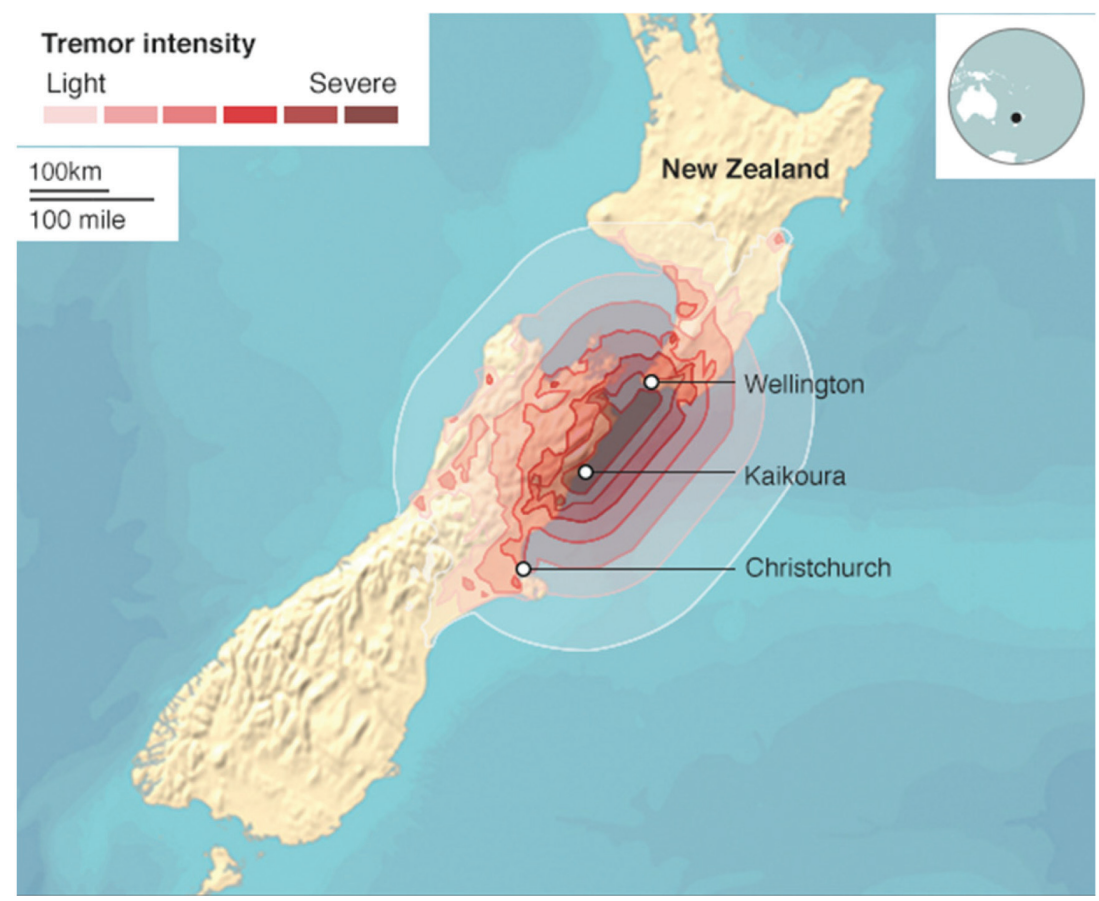

Figure 5: Location map identifying severity and epi-centre of Kaikoura earthquake. (Source: http://www.bbc.com/news/).

Further research has revealed that rather than five faults rupturing, as previously thought, at least 21 fault lines ripped apart - possibly a world record for the number of faults rupturing in a single earthquake. Fourteen of these faults were so violent, the land moved by more than a metre [6].

The final ingredient in this regulatory recipe is legislative. Currently, New Zealand has a strong environmental statutory framework, the backbone being the Resource Management Act 1991 (RMA), which seeks to promote the sustainable management of natural and physical resources in a way that enables people/communities to provide for their social, economic 
and cultural well-being (and for their health and safety), whilst avoiding/remedying/mitigating effect on the environment. This is supported by the Local Government Act 2002 (LGA), The Land Transport Management Act 2003 (LTMA), the Building Act 2004 (BA), the Conservation Act 1987 (CA), and the Marine Mammals Protection Act 1978 (MMPA), amongst others. Various supporting national, regional and district documents outwork the key strategies of the legislative framework.

The Civil Defence Emergency Management Act 2002 (CDEMA) aims to improve and promote the sustainable management of hazards in a way that contributes to the social, economic, cultural and environmental well-being and safety of the public and encourage/enable communities to achieve acceptable levels of risk.

The New Zealand Tourism Board Act 1991 (NZTBA) is enacted by a Tourism Board, whose job it is to create tourism strategies and advise the government and tourism industry on matters related to these strategies.

Whilst independently of each other these industries and legislative/regulatory bodies are active and relevant within their sphere of influence, collaboration seems to be thin, with no easily recognisable linkages or transferable tools that the wider users of the system (i.e. 'the public' or 'communities' or 'business operators') can either rely upon for continuity, or expect enforcement of, or provide a level of uniform expectation.

This article seeks to collectively discuss the 'ingredients' raised above, based on experience working in the field of regulatory planning in New Zealand, including past and ongoing consultancy work for a wide range of stakeholders, as well as reference to recent publications. The overall purpose is to stimulate thinking, discussion and action towards utilising currently available resource management tools as a standard mechanism for ensuring tourism related businesses and communities are proactive in preparing for and responding to large scale natural hazards.

\section{A CUP OF COMMON SENSE}

From the introduction above, the following assumptions have been made:

- New Zealand cannot ignore its vulnerability to natural hazards, particularly the risks of ongoing seismic activity.

- The New Zealand Tourism Industry has undergone exponential growth over the past ten years and is not expected to slow into the future.

- New Zealand's 'clean green' image clearly markets a link between the environment and tourism, however there is no clear legislative direction or collaboration that incorporates natural hazard risk in a cohesive response.

As an exercise in curiosity, the legislations referred to earlier (environmental, civil defence and tourism related) were explored using basic word searches, including 'tourists/tourism', 'visitors' and 'natural hazards/earthquakes'. The basis of this was to determine how many obvious linkages/specific references occur in New Zealand's statutory framework.

The environmental backbone of New Zealand's legal system (RMA, LGA \& LTMA) does not refer to 'tourists', 'tourism' or 'visitors' at all. A single cursory reference in the LTMA refers to tourism within a definition for 'excluded passenger service', which has no direct relevance to the context of this paper. Neither does the CDEMA make any reference to tourism. Whilst one may argue that the use of more generalised nouns ('public' 'people' and 'communities') are inclusive of visiting populations, the lack of any direct acknowledgement 
of visitors to our shores may be likened to a home without hospitality - uninviting and unprepared.

Out of ten different Acts reviewed, only four mention tourism, and one mentions visitors, whilst six refer to natural hazards and seven refer to earthquakes. One presumption is that while New Zealand may be informed of (and prepared for) the risks related to natural hazards within the natural environment, they do not, as yet, inform (or prepare) the tourism industry via environmentally focussed legislation. In contrast, there is the Conservation Act and Reserves Act, which do have a focus on tourism, but few references to natural hazards.

Laws are passed to make improvement and produce better outcomes and legislation is used as an instrument to change behaviour and shape society in various ways, whether it be the economy, the environment, health, housing, education or crime. The RMA in particular, has a central purpose of 'sustainable management' - that is, growth within the constraints of the environment. Yet how is it that the growth in tourism and associated potential effects on the environment (and the impact of the environment on people by way of natural hazards) is severely underrepresented within NZ environmental legislation?

The mechanism of National Environment Standards (NES) and National Policy Statements (NPS) under the RMA umbrella allow for government statements of intent regarding matters of national significance. These contain objectives and policies that councils must 'give effect to' in their regional and territorial plans. Currently there are only five NPS Coastal Policy (required by law), Freshwater Management, Renewable Electricity Generation, Electricity Transmission and most recently, Urban Development Capacity. Only five NES have been set in regulation since 1991, a fact which Sir Geoffrey Palmer (one of the original architects of the RMA) suggests is a gross underutilisation of a potentially very effective tool [7].

In addition, the New Zealand Planning Institute and the Productivity Commission have independently commented that: 'There are just too many plans and consequently too many varied planning responses to the same issues across region[s]. This has resulted in ineffective and inefficient planning and resource management outcomes' [8]. And: 'the lack of integration between the RMA, the Local Government Act 2002 and the Land Transport Management Act 2002 causes difficulties and should be addressed. The legislation makes it too difficult to integrate decisions about land use, transport and housing... [there is also] insufficient responsive infrastructure provision, a sluggish planning system and some in-built incentives to oppose the growth of cities' [9].

Recent proposed amendments to the RMA in 2015 recommend including 'natural hazards' within Part 2, which is seen by planning practitioners as common sense: that councils must 'recognise and provide for...the management of significant risks from natural hazards' [10].

Taking this a step forward, introducing a National Policy Statement that outlines objectives and policies related to effects of tourism on the environment in addition to the effects of the environment on tourism would allow a gateway for territorial authorities to create and strengthen new links between tourism, natural hazards and local government processes. This would improve cooperative governance for community sustainability and resilience before, during and after such an event as the Kaikoura earthquake presented.

For example, the Kaikoura earthquake resulted in significant landslides which cut off road and rail access completely, isolating the township and outlying district from the rest of New Zealand. The Hurunui/Kaikoura Earthquakes Recovery Act 2016 [11] fast-tracked legislative powers to rebuild infrastructure and aid with economic and community recovery, however if an NPS related to tourism existed, local government (in this case Canterbury Regional 


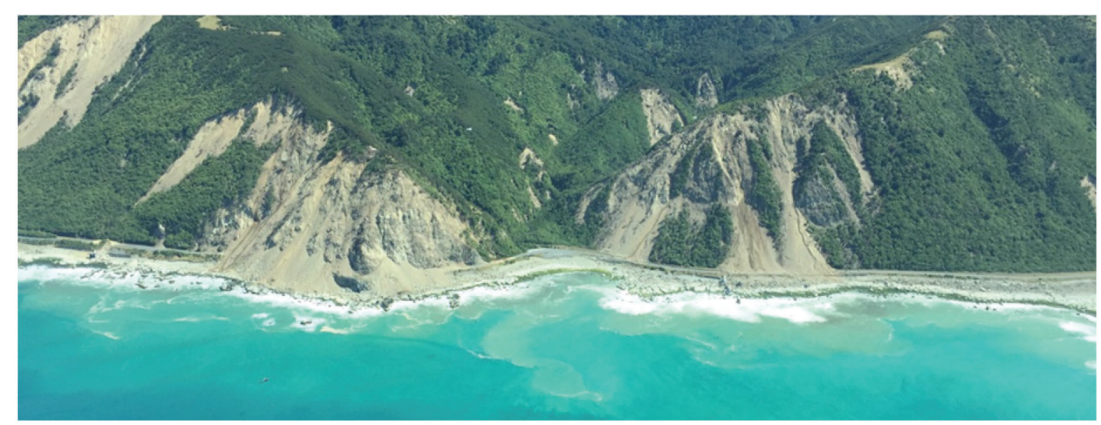

Figure 6: Access to Kaikoura from the north along the main State Highway was completely devastated. (Source: Wings over Whales flight, 11 Feb 2017).

Authority and Kaikoura District Council) may have had more strategic goals in place relating to such a scenario. Informal talks with residents/tourism operators during a recent visit identified that some would prefer the coastal road to remain just that - a road serving tourists and cyclists only, rather than being reconstructed into the main route south. This would enable Kaikoura to establish as a destination in its own right, rather than a drive by attraction. However, the urgency to re-open the road does not allow the luxury of such an option to be explored, and any potential opportunity for creative and collaborative planning is restricted.

\section{A TEASPOON OF TOOLS}

There are a wide range of planning tools at the disposal of local government that could be utilised to coordinate the approach between tourism and natural hazards. The direction for these may be set by the NPS process discussed above, and include: territorial plans, the resource consent process, the building consent process, Land Information Memorandum (LIM's) under the Local Government Official Information and Meetings Act 1987 (LGOIMA) and hazard registers. Wider tools available include structure plans, growth strategies, IWI management plans, tourism and visitor action plans and community response plans (managed under the CDEMA). While there is no shortage of tools that have been implemented at a local level as a direct response to environmental or economic issues within a given community (and the list above is by no means complete), this paper suggests that there is no focus - the recipe now has too many ingredients and too many cooks, and is too complex.

More research and findings should be written in plain language and in a format familiar to planning practitioners and decision makers. Practical tools that are already available need to be explored for additional capacity and application. One such tool it the humble resource consent process. In brief, a resource consent provides permission to carry out an activity that would otherwise contravene certain sections of the RMA (that relate to land-use, subdivision, coastal marine, rivers and lakes, water, discharge of contaminants, noise and general adverse effects) so long as it complies with any conditions attached to the consent. Rules contained within regional and district plans determine whether an activity is considered permitted, controlled, restricted discretionary, discretionary, non-complying or prohibited (Section 87A, RMA).

While some natural hazards such as land stability, flooding and inundation are well registered in NZ and therefore taken into account during the consent process, other less measurable and unpredictable hazard risks (such as seismic or volcanic) are generally ignored (from the 


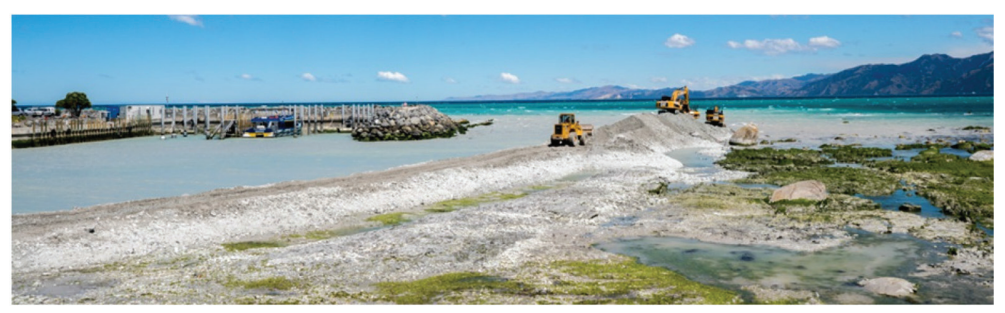

Figure 7: Repair to the Kaikoura Harbour, which rose 1-2 m during the earthquake emergency works are occurring under section 330 of the RMA. (Source: T Madsen, $\mathrm{Feb}$ 2017).

writer's experience in assessing resource consents). As New Zealand is located entirely within the 'ring of fire' band of fault lines, adverse effects of tourism activities and development on the environment in this regard is difficult to predict or plan for. Whilst the resource consent process has been utilised in the response and recovery phases of the Kaikoura earthquake (and previous Christchurch earthquakes) by way of 'fast-tracking' consents to repair infrastructure such as roading, rail and access to the marina - it has not been exploited as a tool to link tourism operators and communities that experience high visitor numbers directly to the civil defence framework prior to any large scale natural disaster occurring.

Applying a standard suite of natural hazard management conditions to every resource consent granted would allow Council to cross-pollinate and streamline training, education and information and business continuity planning/emergency response plans, requiring the monitoring of such conditions be coordinated with the Ministry of Civil Defence and Emergency Management and the Ministry of Tourism. In the context of this paper, this would include every application to undertake a tourism-related activity; however, in the context of New Zealand, this could eventually include every application for land-use development. While traditionally the RMA has been utilised to avoid, remedy and/or mitigate adverse effects of development on the environment, future application might see the RMA seek to enable people and communities to proactively provide for their social, economic and cultural well-being and for their health and safety by preparing for potential adverse effects of large scale natural hazards. Resource consents are a familiar and well utilised tool within the tourism industry and utilising the process to network civil defence, tourism and planning in a single spoon could simplify the regulatory recipe profoundly.

\section{A TRUCKLOAD OF COOPERATION}

As mentioned earlier, the fundamental building blocks to interlock planning, natural hazards and pressures associated with the growth of tourism have been duly established and are well grounded within New Zealand's legal system. However, mechanisms to link these separate processes could be considered stunted at best. While recent seismic events have put pressure on central and local government to refine and strengthen responses to and between natural hazards and planning, the economy and business of tourism remains on an island of its own. If the Kaikoura earthquake had occurred during the day, rather than at night, the local community of 3500 and visiting population of approximately 1000 may have experienced more serious consequences in terms of injury and death. While some would argue that local government is not directly responsible for the health and safety of people and communities, section 11A (d) of the LGA 2002 considers the avoidance or mitigation of natural hazards as 


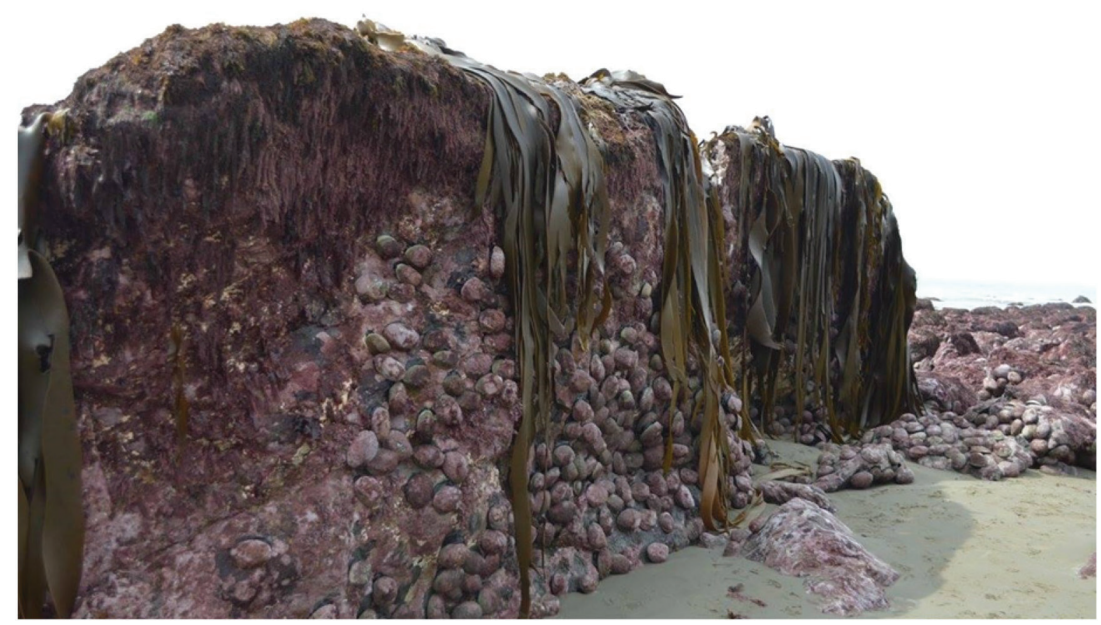

Figure 8: The coastline has been thrust up to $2 \mathrm{~m}$, exposing Paua and Koura (Crayfish) above the high tide mark in some areas. (Source: Facebook/Anna Redmond).

a core service of local authorities. Fundamentally, natural hazards in populated areas cannot be considered independently of the adverse impact they have on people - as much as we utilise the resource consent process to minimise adverse effects on the environment, the end result always includes the health, safety and well-being of the public - both local communities and visitors alike.

In the immediate aftermath of the Kaikoura Earthquake, it was a combined response between Te Rūnanga o Ngāi Tahu (local Maori community in Kaikoura), Kaikoura District Council, Civil Defence, tourist operators and community members that ensured the stranded tourists were accounted for and hosted until they could be evacuated. Crayfish and Paua were served by local fishermen and Te Rūnanga o Ngāi Tahu, and tourists slept at the local Marae (Maori meeting house/grounds). Tourist operators (such as 'Wings over Whales') provided air transport for emergency services, reconnaissance flights and access to check on remote communities; civil defence coordinated with other government response groups to check public safety and organise supplies and access, along with local and regional council involvement.

While collaboration was apparent in the immediate response to the Kaikoura earthquake, (as is often the case when urgent action is required), it is this level of cooperation that communities and authorities should engage in during times of non-conflict. As a planning practitioner, too often it becomes apparent that there is limited involvement of key stakeholders either due to misconception regarding RMA processes or the lack of follow-through from policy to practice.

In summary, a recipe is only as good as the quality of the ingredients. Whilst New Zealand has a strong tourism economy and environmental legislation, the mix as yet is not working and it is considered that available tools, such as National Policy Statements (at the national level) and the resource consent process (at the local level) are underutilised. Both central and local government need to cooperate with each other, and with external organisations (both statutory and non-statutory) to achieve the perfect recipe before the next big shake-up down-under. 


\section{ACKNOWLEDGEMENTS}

The author would like to acknowledge discussions held with Professor David Simmons, Professor of Tourism/Director of Research Strategy and Development, Lincoln University and Mr. Vernon Rive, Senior Lecturer in Law and Associate Head of School - External Relations, Auckland University of Technology, and the research papers they provided for recommended reading. In addition, thanks to Talman Madsen Photography for the majority of photos included, unless otherwise referenced.

\section{REFERENCES}

[1] International visitor arrivals commentary; Ministry of Business, Innovation \& Employment (Hīkina Whakatutuki), available at http://www.mbie.govt.nz/info-services/ sectors-industries/tourism/tourism-research-data/international-travel/international-visitor-arrivals-commentary (accessed 18 February 2017).

[2] 2013 Census QuickStats about a place: Dunedin City; Statistics New Zealand, available at: http://www.stats.govt.nz/Census/2013-census/profile-and-summary-reports/ quickstats-about-a-place.aspx?request_value=15022\&tabname (accessed 19 February 2017).

[3] Tourism Data \& Statistics, available at http://www.tourismnewzealand.com/about/ about-the-industry/ (accessed 19 February 2017).

[4] Barrell, D.J.A., General distribution and characteristics of active faults and folds in the Kaikoura District, North Canterbury. GNS Science Consultancy Report 2014/210 \& Environment Canterbury Report No. R15/23, p. 3, 2015. available at: www.kaikoura.govt.nz/assets/Docs/Council/Publications/GNS-CR-2014-210-Kaikoura-Districtactive-faults-web-version.pdf (accessed 18 February 2017).

[5] Orchiston, C., Tourism business preparedness, resilience and disaster planning in a region of high seismic risk: the case of the Southern Alps, New Zealand. Current Issues in Tourism, 16(5), pp. 477-494, 2013. https://doi.org/10.1080/13683500.2012.741115

[6] https://www.nzgeo.com/audio/kaikoura-quakes-21-faultlines-could-be-world-record/

[7] Ruminations on the problems with the Resource Management Act, Sir Geoffrey Palmer QC, Keynote address to the Local Government Environmental Compliance Conference 2 - 3 November 2015. available at: https://www.planning.org.nz/Attachment?Action= Download\&Attachment_id=3538

[8] Wellington Region Local Government Review Panel, Future Wellington-Proud, Prosperous and Resilient (Wellington October 2012) para. 515.

[9] New Zealand Productivity Commission, Using Land for Housing (Wellington October 2015). available at: http://www.productivity.govt.nz/inquiry-content/2060?stage $=4$

[10] New Zealand Legislation, Parliamentary Counsel Office, Resource Legislatioin Amendment Bill. available at: http://www.legislation.govt.nz/bill/government/2015/0101/latest/whole.html

[11] New Zealand Legislation, Parliamentary Counsel Office, Hurunui/Kaikōura Earthquakes Recovery Act, 2016. available at: http://www.legislation.govt.nz/act/public/2016/0102/latest/whole.html 